\title{
International Journal of Electronics and Electrical Engineering
}

\section{CONTENTS}

\section{Volume 3, Number 5, October 2015}

\section{Electrical and Power Engineering}

Efficient Power Transmission with Existing Grid System of Bangladesh

Aktabujjaman, S. Islam, and M. A. Ullah

Voltage Mode Quadrature Oscillator Employing Single Differential Voltage Current Controlled Conveyor Transconductance Amplifier

\section{S. Maiti and R. R. Pal}

Analysis and Simulation of Novel Single-Ended Forward Bi-Directional DC-DC Converter .349

Jiamei Xu and Lei Li

Simulation of Blackout Recovery in Transmission Side Using N-R Method

G. Naveen and A. A. Jain

Design and Fabrication of I-Cycle

S. V. Pavan Kumar Maddukuri and Borla Srikanth

Electronics and Communication Engineering

Realization of Different Multiplexers by Using COG Reversible Gate.

S. Mamataj, B. Das, and A. Rahaman

FPGA Controlled Simplified H-Bridge Multilevel Inverter

P. Suresh, R. Kavin, B. Jayamanikandan, and S. Anbumani

Design of a Tunable Active Low Pass Filter by CMOS OTA and a Comparative Study with NMOS OTA with Different Current Mirror Loads

T. K. Das and S. Chakrabarti

Design and Analysis of an X-Band Isolator Coupled to an Accelerating Manifold

Junaid Zafar, Tasneem Zafar, Andrew A. Gibson, and Haroon Zafar

Design and Development of an Android Accessory

F. C. Serce, A. Erpay, A. Erpay, B. Unal, D. Ozgubar, A. Ozturk, and S. Sekerci

Modeling of Wavelength Conversion Using Switching Bistability in a Vertical Cavity Semiconductor Saturable Absorber

L. Mishra, P. K. Datta, and R. Pradhan

Multiband Star Shape Slotted Micro-Strip Patch Antenna Design for Wireless Application 402

S. Kumar and D. Chandra 


\section{Control Systems}

Control of Air Conditioning Systems Using Neural Network . .406 Mithilesh K. Yadav and Dinesh Chandra

Industrial Noise Cancellation System-Model .....

Gourab Moitra 